\title{
Acompanhamento Terapêutico no Centro Cirúrgico
}

\author{
Pinto, Stela Duarte; Cotrim, Ana Moreira; Rodrigues, Karine Cândido; D 'Afonseca, \\ Mariana Gonçalves
}

Instituto do Câncer do Estado de São Paulo — stela.duarte@icesp.org.br

Introdução: o Centro Cirúrgico (CC) pode ser considerado um ambiente estressante, que pode ser percebido pelo paciente como uma ameaça real ou imaginária. Isto irá depender da vivência de experiências anteriores, características de personalidade e do tipo de informação obtida em relação ao procedimento cirúrgico. Existem pacientes com indicação cirúrgica que desistem ou adiam a cirurgia devido à falta de informação, fantasias e sentimentos, como medo e ansiedade. Estudos mostram que a informação e a intervenção psicológica podem diminuir o grau de ansiedade e auxiliar o paciente no processo de enfrentamento de sua doença e dos medos associados à cirurgia, embora alguns ainda assim, permaneçam com altos níveis de ansiedade e requeiram suporte até o momento da cirurgia. Devido a estes fatores e visando uma prática humanizada, para atender a demanda singular de cada paciente, o Serviço de Psicologia Hospitalar de um hospital oncológico público percebeu a necessidade da criação de um programa de acompanhamento aos pacientes no CC. Objetivo: Acompanhar pacientes com câncer no período pré-operatório, desde a ida ao centro cirúrgico até o momento da anestesia; atuar diante de quadros psico-reativos; orientar e fornecer suporte terapêutico ao paciente frente à cirurgia, minimizando o nível de ansiedade durante o período pré-operatório mediato e imediato. Método: Os pacientes, após serem admitidos na unidade de internação são avaliados pela equipe de psicologia. Nesta triagem inicial, são avaliados: nível de ansiedade, sofrimento psíquico, grau de conhecimento da cirurgia, mecanismos de defesa, recursos de enfrentamento, postura frente à doença e hospitalização, além de manifestações psíquicas e comportamentais. Após esta avaliação, verifica-se a necessidade de acompanhamento ao $\mathrm{CC}$ e o desejo, por parte do paciente, de ser acompanhado pelo psicólogo. Resultado: o programa "Acompanhamento Terapêutico no CC", iniciou-se em outubro de 2009 e foram acompanhados até dezembro de 2013, 102 pacientes. Os que receberam este suporte mostraram-se menos ansiosos e mais seguros para a realização do procedimento. Conclusão: o acompanhamento terapêutico no CC pode ser uma estratégia para reduzir a ansiedade, o medo e suas repercussões em pacientes com câncer; além de contribuir para uma compreensão mais ampla sobre o processo, fortalecendo recursos de enfrentamento diante da intervenção cirúrgica, sendo um programa voltado para a humanização, uma vez que contribui para uma atenção integral do paciente.

Pinto, Stela Duarte; Cotrim, Ana Moreira; Rodrigues, Karine Cândido; D`Afonseca, Mariana Gonçalves. Acompanhamento Terapêutico no Centro Cirúrgico. In: Anais do Congresso Internacional de Humanidades \& Humanização em Saúde [= Blucher Medical Proceedings, num.2, vol.1]. São Paulo: Editora Blucher, 2014. ISSN 2357-7282

DOI 10.5151/medpro-cihhs-10744 